\title{
City rhythms of commuter traffic Decarbonisation of commuting in Vienna
}

\author{
Gerda Hartl \\ Institute of Architectural Sciences: Digital Architecture and Planning, Vienna University of Technology \\ Vienna, Austria \\ hartl@iemar.tuwien.ac.at
}

Received: November 15, 2019. Revised: October 6, 2021. Accepted: October 29, 2021. Published: November 14, 2021.

\begin{abstract}
Today's distribution of residences and workplaces is a result of availability of cheap oil combined with human preferences for residence in low-density areas. Having reached Peak-Oil nowadays, common motorised mobility is under scrutiny: Not only its massive $\mathrm{CO} 2$ output but, most of all, its future scarcity demands urban and regional planning to anticipate the sustainable city of the future. In our work, we have looked at the city of Vienna, in which we have researched patterns of mobility regarding commuters. Our final goal is redensification as a means for transformation of the present state into a walkable city. To make that possible, our analysis provides insights into necessities of mode switching, according to the distances from workplaces. The model which we present is applicable not only to our research area, but to a variety of cities that want to achieve a sustainable settlement structure.
\end{abstract}

Keywords-commuting; traffic; city rhythms; decarbonisation; system theory; transport demand model; walkable cities; sustainable settlement

\section{INTRODUCTION}

Cities can be considered dynamic systems consisting of various synchronized processes happening in space-time [12]. Space uses including traffic can be viewed as stable processes because they tend to return to their initial conditions and tend to recover after disturbances. The daily intra-city commuting rhythm, which exchanges basic day and night population, is such a process. Its causes are that workplaces tend to agglomerate while residences tend to disperse in functionally differentiated societies [12].

Latest research utilising mobile telephone positioning data elucidates that human trajectories show a high degree of temporal and spatial regularity [14] and exhibit a significant probability to return to few highly frequented locations (as defined by using Zipf's law distribution for all visited locations) in definite time spans [14]. Concluding, home residence and workplace are basic anchor points for commuters (home residence is also denoted as "center of life" in the Austrian legal definition of primary residence), evoking the more specific spatio-temporal rhythms in between them the more distant they are located due to restricted time for unplanned trips [16]. This new data source may substitute scarce travel survey data mined on aggregate levels at intervals of 5 or 10 years only [13].

Because time and space are a closely interlinked system, wider reach due to higher speed as provided by motorised modes with regard to constant travel time [21] has step-by-step detached differentiated functions in space and forms a selfreinforcing system of high external energy usage. Motorised rush hour traffic in the cities is downgrading the quality of life in terms of time and pollution.

In our research we focus on commuter traffic to elaborate the implications of uneven densities, functional detachment and variable accessibility throughout the city landscape. To cast a light on today's commuter relations in Vienna, we build a commuter model based on census data which we assign to the street network of the "transport model Vienna" of the city of Vienna. In doing so, we determine characteristics of travel dimensions. Traffic densities on the street segments of the city caused by pedestrian, bicyclist and private car commuters will be shown as well.

\section{BACKGROUND}

Transport demand models try to solve the threedimensional problem of origins, destinations and mode choice of paths undertaken by homogeneous groups of humans for certain purposes. The area of interest is comprised of traffic zones, which largely correspond to administrative zoning due to data availability. The sorts of traffic to be considered by the model are: internal traffic, originating traffic, terminating traffic, through traffic. For the sake of completeness we may also consider the inclusion or exclusion of traffic originating or ending in the surrounding areas.

A transport demand model is essentially a closed system: Whatever originates in a zone of the model has to terminate in a zone of the same model, too. Demand and supply of workplaces are modelled at the gravity points of zones, which access the transport network via feeder links. Distances are either approximated by line-of-light-flight lengths in combination with detour-factors, or they are modelled as links and nodes of a circulation system. The latter aspect can be computed e.g. by using software like VISUM (PTV AG) [17]. Summarising, a main aim of such models is generating a plausible image of the actual traffic volumes in a given area of interest [18]. This is accomplished via comparison of the model's traffic density values obtained by assignment at traffic counting points (e.g. private transport). Also, a traffic zone's outgoing volume can be compared to traffic surveys available for the outgoing traffic of this specific traffic zone. If the model is congruent with counting, the prediction of future traffic loads due to changed conditions (establishment of new housing or 
shopping facilities, breaking up of existing transport links or addition of connections) becomes feasible. Yet, human decisions are complex and traffic census data is remarkably | rare. For the case of Vienna, very few traffic-counting points are observed (mechanically), while the purpose of travel is obliterated completely [4]. This implies that a model of Vienna's commuter flows thus built and calibrated cannot produce any valid results.

A transport model is normally subdivided into four steps: traffic generation, traffic distribution, modal choice and traffic assignment. Consumers (demand) are first distributed to destinations using specific functions (e. g. gravity functions); then, this demand is distributed to the available transport modes using specific functions (e.g. Kirchhoff's law). In the end, the achieved origin-destination matrices for the considered transport modes are attributed to routes of the network, thus visualising traffic density on links.

In literature, this approach was criticised due to the fact that humans evaluate potential goals and how to reach them by the available modes, before settling on a path [5]. Today's simultaneous transport demand models like the generationdistribution-mode choice model "EVA" [5] solve this inconsistency by calculating consumer choice on destination and transport modes at the same time. This simultaneous distribution is based on separate accessibility matrices and is a more realistic model of human choice behaviour; yet, it results in immediate changes in destination and mode choice of consumers, once accessibility values are altered. Thus, for our needs, this kind of model is not appropriate because commuters do not change their workplace in a short term if accessibility worsens. For example, it is mentioned that decisions for residence and workplace are processes [12], which happen at an average timeframe of up to 5 years and more.

Returning to the description of the approach commonly used, there is always a component that looks into the future. For example, land-use transport models for urban regions are used for simulating changes in space utilisation and transport for periods of one to five years. Land use and transport are closely intertwined; the change of either influences the other. Such models intend to make future macroscopic developments of these two entities tangible [8]. Comprising plenty of submodels and complex functions within and between them, they are highly aggregate and necessarily based on many assumptions.

We neither aim to construct a transport demand model nor do we target at building a land-use transport model. The key point of our approach is that we want to deal with census data only, and, more importantly, we do not wish to model changes in land use, transport or people's decisions as a reaction to varied circumstances. Rather, we are interested in the decarbonisation solution space [10], looking at today's distribution of commuters, workplaces and their inter-linkages throughout the city of Vienna, as stated by our commuter model. Opposing to the status quo, we aim to show scenarios of reduced energy consumption. The underlying idea is that no external energy is used, and therefore, no toxic emissions are output.

\section{MODEL OF COMMUTER RELATIONS IN VIENNA}

\section{A. Terms and extent}

In our research, we focus on intra-city commuters exclusively, who are employees residing and working in Vienna. So-called non-commuters, employees who work from their home residence are eliminated because they do not commute to their workplace. In Vienna, statistical data [1] comprises 591.000 intra-city commuters of which $41 \%$ (241.000) use private cars, 47\% (280.000) public transport, $11 \%$ (63.000) walk and 2\% (7.700) use a bicycle to reach their workplace [23]. We assumed that commuters using a private car do not take other commuters with them as passengers but rather drive alone to their workplace. Thus, a commuter going by private car always equals a car on the road. We agreed to show morning rush hour traffic because characteristics of oneway trips are easier to interpret. Evening traffic routes would change but this is not essential for our purposes at the moment.

\section{B. Transport Model (Verkehrsmodell Wien der Stadt Wien)}

The transport model of the city of Vienna (so-called "Verkehrsmodell Wien der Stadt Wien", further abbreviated as "VMW"), which we received from the MA 18 Stadtentwicklung und Stadtplanung, is implemented in PTV AG's software VISUM [17] and consists of 281 traffic zones. This zoning is in principle based on the administrational zones established by Statistics Austria [20] for census counts. These administrational zones are one level smaller than the 23 districts of Vienna, the so-called "Bezirke" (further abbreviated as "B"). A district thus consists of few or many so-called "Zählbezirke" (further abbreviated as "ZB"), dependant on the relative size of the district as compared to other districts of Vienna. The districts "Floridsdorf" and "Donaustadt" (numbers 21 and 22 in Figure 1) which are located in the east of Vienna on the other side of the Danube and the districts "Hietzing" and "Penzing" (numbers 13 and 14 in Figure 1) in the far west of the city containing big parts of forest are all much bigger than the other more centrally located districts in proximity to the core historic district, "Innere Stadt" (number 1 in Figure 1). Thus, ZBs of these districts are usually more in number and bigger due to less population and more open green space (see Figure 1). A feature having complicated data interoperability for us was that some ZB as defined by Statistics Austria have been subdivided further in the VMW. This is a quite usual approach since the builder of a transport model considers many factors when deciding on a zoning strategy. Thus we adjusted the data we retrieved from Statistics Austria to this different zonal apportionment. 
Fig. 1. zonal model on $\mathrm{ZB}$ basis inclusive pedestrian network

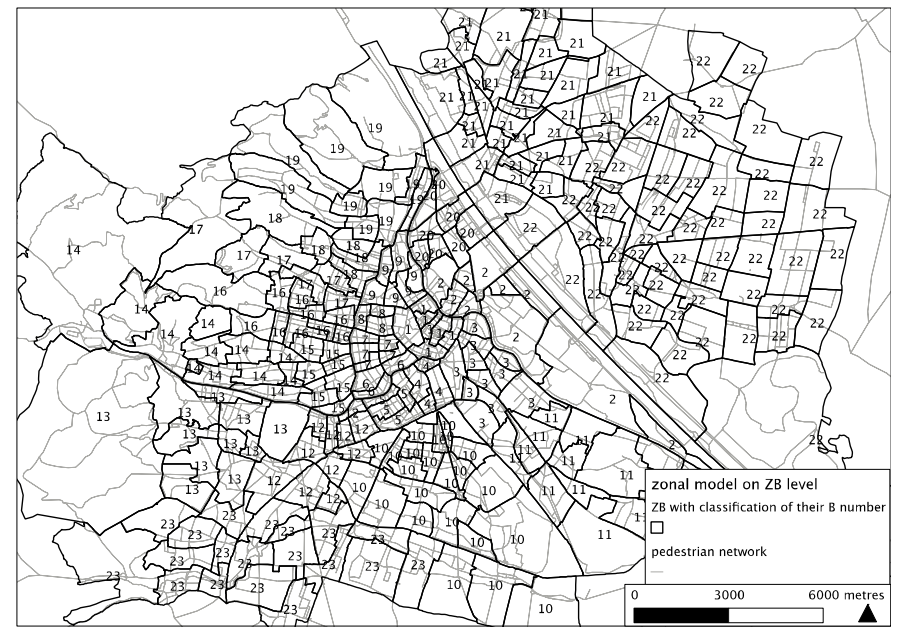

The network model of the VMW consists of links, turns and feeder links for all transport modes respectively (pedestrian, bicyclist, public transport and private transport). Metric lengths are incorporated in links; for the service-routes of public transport travel times are known also because of the fixed timetable of service. Feeder links are necessary to enable routing to start and end at gravity points of traffic zones. Feeder links incorporate metric lengths and times for passing for all transport modes (pedestrian, bicyclist, public transport, private transport). Turns only exhibit values of waiting times after assignment calculation. All links are directed, restricted to certain transport modes and to certain maximum speeds. Not all streets and paths of Vienna's real network are included due to the fact that modelling such a detailed network with all its inherent values is extremely time consuming.

As an addition to the VMW we used data on the administrational level below the before mentioned $\mathrm{ZB}$ also, which are the so-called "Zählgebiete" (further abbreviated as "ZGEB"). Building blocks, which form the administrational level below the ZGEB constitute the end of further downscaling (see Figure 2), were available as well [19]. We elaborated our data structure to fit manifold purposes of research on these levels of scale. Especially the spatial database we built on the level of ZGEB will be very useful once we perform the next step which considers how to re-allocate commuters as to match our scenario of Vienna as a "walkable city".
Fig. 2. Zonal model on ZGEB basis inclusive building block zoning

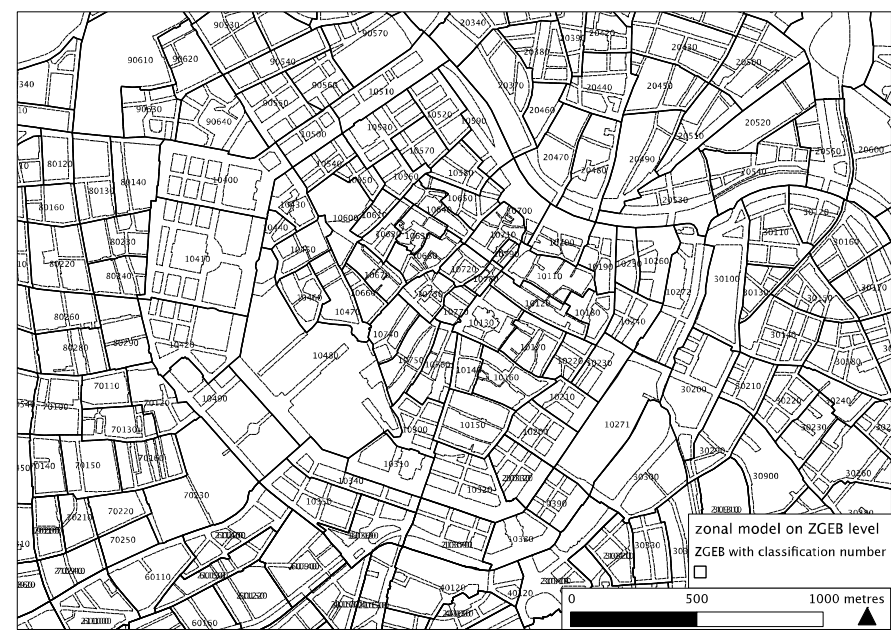

\section{Structural Data}

We obtained quantitative data on residents, places of employment, workplaces, households, residences, commuters and mode choice of commuters from manifold sources. Places of employment subsume workplaces; therefore workplaces equal employees by this definition.

Data on commuters, workplaces and residents on the level of ZB was provided in the VMW, therein called "input data for traffic generation purposes" [2]. Data on residents, places of employment, households, residences and secondary residences was taken from [3]. The total of 591.000 intra-city commuters of Vienna are available as a $23 \times 23$ matrix of commuters on the level of B [1]. On the same level $23 \times 23$ matrices containing the mode split of intra-city commuters to the transport modes pedestrian, bicyclist, public transport and private transport are available [23]. Thus it is clear, which origin-destination paths commuters realise by which transport mode.

We harmonised workplace and resident numbers on the level of ZB from [2] to match data of 2009 workplaces (ÖNACE) [20] and 2011 (census) [20] on the level of B. This we did via shares of $\mathrm{ZB}$ values [2] as parts of their sums (which form $B$ values).

To break down the commuter matrix from the level B to the level $\mathrm{ZB}$ we first obtained ratios of workplaces on the level of ZB [2] as compared to their sum on the B level. We performed the same operation with regard to commuters on the level of ZB [2]. Then, by the help of these ratios, we first distributed commuters at residential locations on the level of $\mathrm{B}$ [1] to the level of ZB. Next, we distributed these new numbers of commuters at $\mathrm{ZB}$ origins to workplaces in the same fashion, using ratios of workplaces on the level of ZB [2]. In doing so, we obtained a $281 \times 281$ matrix of commuters on the level of ZB. We merged this origin-destination matrix with the modal split ratios on the level of B [23] whereas equal mode apportionment as on the level of $\mathrm{B}$ was assumed. The global mode split which results from these new ZB matrices of commuter relations, reflects data on global mode choice of commuters again [7]. 
The $281 \times 281$ matrix of commuters' origins, destinations and mode choice is our quantitative commuter model which we next use for traffic assignment to visualise the daily impact of commuting on the transport network (see Figures $3 a, 3 b, 3 c$, $3 d)$.

\section{Assignment Model}

To broaden the scope of our commuter model we calculate stochastic traffic assignment with VISUM to obtain data values from all zones to all zones concerning travel distance, travel time, line-of-light-flight lengths, velocity, resistance and route choice for the transport modes pedestrian, bicyclist and private car. To obtain these travel indicators we assign the basic demand matrices (provided in the VMW, therein called "basic demand matrices") onto the network; actual travel time was used as the basis for calculation of resistance and route-search, for all indicators we assigned the value of 1 to the diagonal. Stochastic assignment is useful for depicting that commuters basically choose "best connections" in the available network, but evaluate them differently due to incomplete or imperfect information [17]. First, routes are mined algorithmically between all zones on the chosen network (pedestrian, bicyclist, private car). Different feeder link times and lengths for all modes help to approximate the parts of routes leading from the gravity points of zones to the network access points. Next eliminating those that only marginally deviate from each other reduces the mined routes. Once routes are thus limited, a distribution function comes into play, which assigns the commuters to the available routes. We used a Kirchhoff function here, with a Beta value of 4 . Using this distribution function, also "suboptimal" routes are used by commuters, which is more realistic than a strict application of Wardrop's principle [17].

The travel indicators achieved are the basis of evaluating accessibility between zones for users of a certain mode. We used these values to elaborate travel length distributions of the pedestrian, bicyclist and private car commuters of our model. It should be noted that not all links are available in the VMW; especially for the pedestrian mode this circumstance implies that accessibility values must be shorter in reality. Figure 4 shows a comparison of travel lengths as utilised by the pedestrian and bicyclist commuters of our model. Graphic representation of route choice visualised as traffic density on street segments provoked by our commuters is displayed in Figure 3a), Figure 3b), Figure 3c) and Figure 3d).
Fig. 3. Traffic density on respective street network as induced by intra-city commuters' way to work: a) cars on the street segments of the car-oriented transport network b) detail of density of cars c) bicyclists on the street segments of the bicycle-oriented street network d) pedestrians on the street segments of the walkable street network
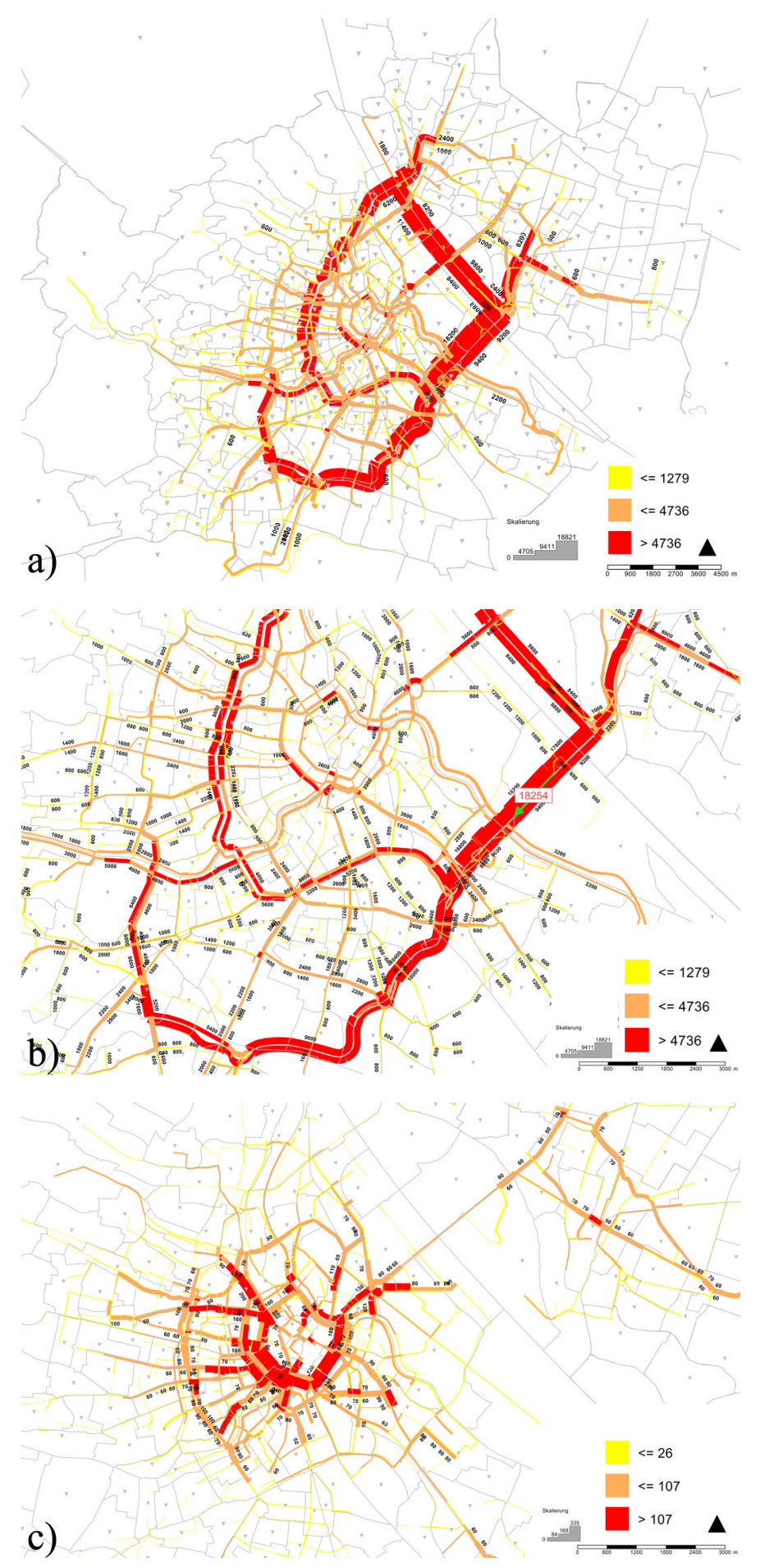


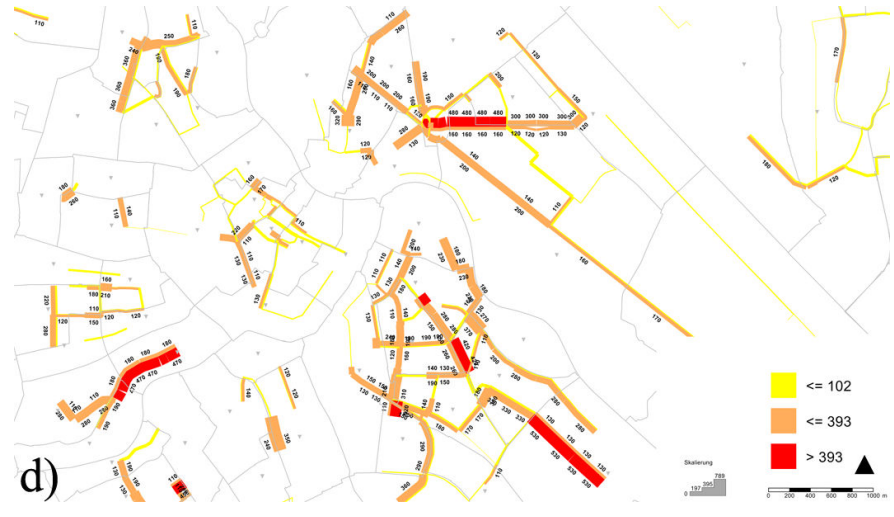

IV. MODE SWITCH SCENARIO

Evaluating the solution space for future walkability in the field of commuter traffic naturally comprises examining changes in transport mode choice, in present-day locations of commuters or present-day locations of these commuters' workplaces. In our mode switch scenario we keep origins and destinations fixed and rather assume transport mode choice to change, being not as basic as a decision for an appropriate residence or workplace. Literature states that users of private transport are very attached to this mode of transport due to body energy savings and temporal advantages of reach [6]. Yet this preference can easily be put aside by restrictions on the level of city governmental laws and orders. For example: Vienna has recently introduced parking space management which limits parking times for the Viennese population and forbids parking for incoming commuters from Lower Austria or Burgenland arriving by private car. Their number (also based on census data [1]) equals $48 \%$ of commuters going by private car in intra-city traffic of Vienna, thus this new sanction is supporting decarbonisation in Vienna to big extents.

In our commuter model pedestrians and bicyclists are to $95 \%$ and to $89 \%$ likely to travel a maximum of 5 kilometres, the rest of them will only accept up to 9 kilometres of travel length. $43 \%$ of commuters using a private car are likely to accept a distance of 5 kilometres, $33 \%$ will accept a distance of 10 kilometres, and the rest of them will travel a maximum of 25 kilometres. On average, our intra-city commuters using a private car drive 7 kilometres (weighed average user-based value of average of distance class) whereas pedestrians and bicyclists walk or ride 3 kilometres in this respect. 1995 data shows that car users in Vienna drive $6,7 \mathrm{~km}$ on average for all purposes [7]. In Lower Austria 50\% of all paths driven by car are below $6 \mathrm{~km}$ of distance. Looking at the distribution of pedestrian and bicyclist commuters below a distance of 10 kilometres in Figure 4, we see that pedestrians and bicyclists are in detail preferring distances below 3 and 5 kilometres respectively.
Fig. 4. Travel length distribution of pedestrian and bicyclist commuters

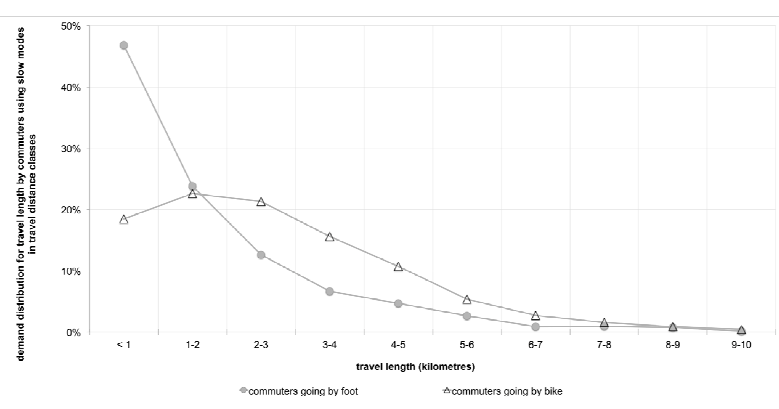

The VMW incorporates a maximum distance of 40 kilometres between zones (and marginal counts of more than that) on the car-oriented street network due to the directed street network and its inherent detour distance. The maximum zonal distance of pedestrian and bicyclist travel lengths is 25 kilometres, which is the diameter of the city.

Knowing the status-quo travel lengths of pedestrians and bicyclists (see Figure 4), we firstly assume that commuters using a private car will from now on walk to their workplace if it is accessible within the travel length that is walked by the pedestrian commuters of our model. Thus, if commuters going by private car can reach their workplace within up to 3 kilometres using the pedestrian network instead, they will turn into pedestrian commuters. Figure 4 shows that up to 3 kilometres are still acceptable for commuters walking to their workplace whereas the preference for lower distances exhibits almost exponential behaviour. These pedestrian distances below 3 kilometres which are now walked by former car drivers on the pedestrian network, are 2,1 kilometres long on average. Because not all pedestrian links are part of the model, this new average walking distance for mode switchers is likely to be lower due to much higher connectivity for pedestrians in reality. This new pedestrian commuting substitutes distances of on average 2,4 kilometres that mode switching car drivers live apart from their workplaces. The velocity of pedestrians in our model is the commonly accepted value of $4 \mathrm{~km} / \mathrm{h} .2,1$ kilometres can be walked in approximately 30 minutes. In Vienna, 39\% of commuters (all modes) travel 16 to 30 minutes on their way to work, $23 \%$ travel less and $38 \%$ more than that [7]. For central regions in Lower Austria a mobility survey of 2008 states that pedestrian walks for all purposes are $1,4 \mathrm{~km}$ long [22]. Although our new pedestrian commuting distance is a bit longer, it is easy to see that for establishing a walkable city a primary goal is that people walk more. Figure 5 shows that this approach reduces the number of commuters going by private car by $28 \%$, travelled commuter-kilometres by car reduce by $9 \%$.

To further confine the mass to be reallocated ${ }_{2}$ we assume that the beforehand-obtained amount of commuters still using the private car will rather go by bicycle to their workplace if it is accessible in the travel length travelled by bicyclist commuters of our model. Thus, if the remaining commuters by private car can reach their workplace within up to 5 kilometres on the bicyclist network, they will turn into bicyclists. Figure 4 shows that up to 5 kilometres are still acceptable for commuters using a bicycle. Here, $11 \%$ of our bicyclists are 
still traveling these $5 \mathrm{~km}$ whereas $13 \%$ of our pedestrians would still walk the before stated 3 kilometres. These new bicycled paths substitute distances of on average 4,9 kilometres that car-driving commuters live apart from their workplace. The mode switching car drivers now ride their bicycles for 4,5 kilometres on average. The average travel distance bicycled in

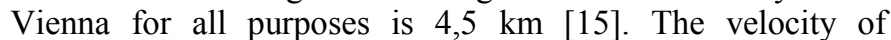
bicyclists in our model is $18 \mathrm{~km} / \mathrm{h}$, whereas $12 \mathrm{~km} / \mathrm{h}$ is a common value [18].

Figure 5 shows that second step of modal switch reduces the number of commuters going by private car by another $18 \%$ for travel lengths shorter or equal to $5 \mathrm{~km}$ on the bicyclist network. Commuter-kilometres by car reduce by another $13 \%$. Hence, a total of $46 \%$ of commuters using the private car today could switch to slow, sustainable modes by such premises alone. These 110.500 commuters fewer reduce driven personkilometres by $20 \%$. Accordingly, energy usage is reduced by this number, as are toxic gases respectively. Energy usage of 6.020 GJ spent originally for paths to work (energy use per private passenger vehicle kilometres [11]) with private cars reduces by $13 \%$ in our mode switch scenario. The remaining commuters still using private cars live on average $11,2 \mathrm{~km}$ apart from their workplace. They will be considered for reallocation.

Fig. 5. Commuters using a private car switching to pedestrian or bicyclist commuting

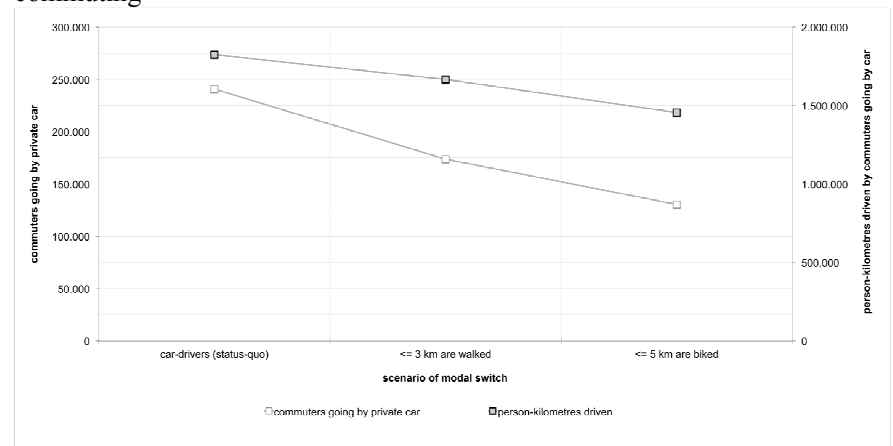

\section{NEXT STEPS}

Keeping commuter's residences and workplace locations fixed we obtained the critical mass of commuters to be reallocated in the next step. In general, changing workplaces seems less desirable since it brings about shifts in already sustainable connections of commuters to their belonging workplaces. Thus commuters will be assumed to change their residence locations rather than the other way round. The research aim is to obtain a spatial distribution of commuters, which offers the option of using sustainable modes on a daily basis. To design this scenario, we will focus on accessibility dimensions and prospective locations for additional densities. Furthermore we will visualise the temporal rhythm of motorised private commuting using Agent-Based-Modelling.

\section{DISCUSSION}

We have shown in our commuter model that travel lengths for pedestrians, bicyclists and private car commuters need to be looked at in a differentiated way: while travel lengths of pedestrians and bicyclists are naturally limited due to body energy savings travel lengths driven by private cars are comparably short. Our scenario of mode switch exhibits that there are options for $46 \%$ of commuters going by private car to change to sustainable modes even though time is scarce nowadays, of course [9]. Altogether, the travel lengths output by our commuter model fit well with traffic survey data.

Commuter traffic is a result of choices of residential locations, workplace locations and mode choices available for the human subject, all of them subject to change. Therefore, the incentive today is to rethink allocation and interlinkages so that the walkable city of the future can become a reality. We believe that our on-going research will help to take an unbiased look at our present-day settlement structure and its corresponding travel dimensions. Our case study of Vienna can exemplify which problems need to be faced by 2020 if thoroughly thinking about a sustainable, liveable future without dependency on oil.

\section{ACKNOWLEDGMENT}

We want to thank the Magistrat der Stadt Wien, MA 18 Stadtentwicklung und Stadtplanung for the provision of the Verkehrsmodell Wien der Stadt Wien. We want to thank the PTV AG Karlsruhe for the provision of a research-license of VISUM.

\section{REFERENCES}

[1] Statistik Austria Bundesanstalt Statistik Österreich, Abgestimmte Erwerbsstatistik 2009, accessible via www.statistik.at/web_de/frageboegen/abgestimmte_erwerbsstatistik/erg ebnisse/index.html

[2] Magistrat der Stadt Wien MA 18 - Stadtentwicklung und Stadtplanung, Verkehrsmodell Wien der Stadt Wien Stand 2009 (VISUM Transport Model, demand matrizes \& input data for traffic generation modeling), received in August, 2012, www.stadtentwicklung.wien.at

[3] Statistik Austria Bundesanstalt Statistik Österreich (ed.), Ortsverzeichnis Wien 2001, Verlag Österreich GmbH, Wien, 2005, p. 1-138, accessed via www.statistik.at

[4] Verkehrsplanung Käfer GmbH, Straßenverkehrszählung Wien 2010: Auswertung Gemeindestraßen A+B: Endbericht, August 2011, p. 1-176, accessed www.wien.gv.at/stadtentwicklung/studien/pdf/b008200.html

[5] Lohse, D., Berechnung von Personenverkehrsströmen, in: Wissenschaft und Technik im Straßenwesen, Heft 17, 1977

[6] Knoflacher, H., Grundlagen der Verkehrs- und Siedlungsplanung, Böhlau Verlag Ges.m.b.H., Wien, Köln, Weimar, 2007

[7] Herry Consult GmbH, Vekehr in Zahlen Österreich Ausgabe 2011, Bundesministerium für Verkehr, Innovation und Technologie Abteilung II/Infra 5 (ed.), July 2012, p. 1-286, accessible via www.bmvit.gv.at/verkehr/gesamtverkehr/statistik/downloads/viz11/inde x.html

[8] Wegener, M., Overview of land-use transport models, in: D. A. Hensher \& K. Button (eds.), Transport Geography and Spatial Systems, Handbook in Transport, Handbook 5, Pergamon/Elsevier Science, Kidlington, 2004, p.127-146

[9] G. Franck, Es wird eng mit der Zeit, p.38-39 in: Die Presse, July 2006

[10] Hartl, G., Franck, G., Modelling the configuration and dynamics of urban space, in: Computational Engineering in Systems Applications, Volume 2, IAASAT Press, July 2011 p. 26-30

[11] Kenworthy, J.R., Transport energy use and greenhouse gases in urban passenger transport systems: A study of 84 global cities, presented at: International Third Conference of the Regional Government Network for Sustainable Development, Notre Dame University Fremantle, September 2003 p. 1-28 
[12] Franck, G., Wegener, M., Die Dynamik räumlicher Prozesse, in: Dietrich Henckel \& Matthias Eberling (ed.), Raumzeitpolitik, Leske \& Budrich, Opladen, 2002, p. 145-162

[13] Ahrens, G.-A., Ließke, F., Wittwer, R., Hubrich, S., Endbericht zur Verkehrserhebung,Mobilität in Städten - SrV 2008‘ und Auswertungen zum SrV-Städtepegel, Technische Universität Dresden, 2009, p. 1-157

[14] Gonzalez, M., Hidalgo, C., Barabsi, A., Understanding individual human mobility patterns, in: Nature, Volume 453, Issue 7196, June 2008, p. 779-782

[15] Magistrat der Stadt Wien MA 18 Stadtentwicklung und Stadtplanung (ed.), Radverkehrserhebung Wien, Entwicklungen, Merkmale und Potenziale Stand 2010, Werkstattberichte Heft Nr. 114, 2011, p. 27

[16] Ahas, R., Aasa, A., Silm, S., Tiru, M., Daily rhythms of suburban commuters' movements in the Tallinn metropolitan area: Case study with mobile positioning data, in: Transportation Research Part C, Emerging Technologies, Volume 18, Issue 1, February 2010, p. 45-54

[17] PTV AG, Ptv vision: VISUM 12 - fundamentals, Karlsruhe, November 2011 , p. 356, accessed via educational license of VISUM 12, received in March 2012
[18] Schnabel, W., Lohse, D., Grundlagen der Straßenverkehrstechnik und der Verkehrsplanung: Band 2: Verkehrsplanung, DIN Deutsches Institut für Normung e.V. (ed.), Beuth Verlag, Berlin, Wien, Zürich; Kirschbaum Verlag GmbH, Bonn, 2011, p. 173 ff.

[19] Stadt Wien, Open Government Data - data.wien.gv.at

[20] Statistics Austria - www.statistik.at

[21] Schafer, A., The global demand for motorized mobility, in: Transportation Research Part A, Volume 32, Issue 6, p. 455-477

[22] Herry Consult GmbH, Mobilität in NÖ, Ergebnisse der landesweiten Mobilitätsbefragung 2008, Amt der NÖ Landesregierung, Abteilung Gesamtverkehrsangelegenheiten, NÖ Landesakademie, Bereich für Umwelt und Energie (eds.), Heft 26, 2008, accessible via www.noe.gv.at

[23] Statistik Austria Bundesanstalt Statistik Österreich, Volkszählung 2001, Daten zu Verkehrsmittelwahl der Berufspendler Wiens, not publicly available.

\section{Creative Commons Attribution License 4.0 (Attribution 4.0 International, CC BY 4.0)}

This article is published under the terms of the Creative Commons Attribution License 4.0

https://creativecommons.org/licenses/by/4.0/deed.en_US 